\title{
The role of telemedicine and mobile health in the monitoring of sleep-breathing disorders: improving patient outcomes
}

This article was published in the following Dove Press journal:

Smart Homecare Technology and TeleHealth

3 February 2017

Number of times this article has been viewed

\author{
Jair A Villanueva ${ }^{1, *}$ \\ Monique C Suarez ${ }^{2, *}$ \\ Onintza Garmendia ${ }^{2,3}$ \\ Vera Lugo ${ }^{2}$ \\ Concepción Ruiz ${ }^{2}$ \\ Josep M Montserrat ${ }^{2-5}$ \\ 'Unit of Biophysics and \\ Bioengineering, Faculty of Medicine, \\ University of Barcelona, ${ }^{2}$ Sleep Unit, \\ Respiratory Medicine Department, \\ Hospital Clinic, Barcelona, ${ }^{3}$ Center for \\ Biomedical Research in Respiratory \\ Diseases (CIBERES), Madrid, ${ }^{4}$ Faculty \\ of Medicine, University of Barcelona, \\ ${ }^{5}$ August $\mathrm{Pi}$ i Sunyer Biomedical \\ Research Institute (IDIBAPS), \\ Barcelona, Spain \\ *These authors contributed equally to \\ this work
}

Correspondence: Monique C Suarez Unitat del Son, Servei de Pneumologia, Hospital Clinic, 170 Villarroel, Barcelona 08036, Spain

Tel +34932275746

Email mcsuarez@clinic.ub.es

\begin{abstract}
Although the concepts are broad, telemedicine and mobile health (mHealth) can be defined as a methodology to provide health care remotely and improve health services and outcomes using telecommunication tools. The widespread adoption of these technologies and current health care challenges, such as the aging population and increasing costs, has encouraged interest in the development of new strategies involving telemedicine. Overall, there is a lack of evidence rigorously assessing the impact of telemedicine and mHealth. Therefore, proper randomized controlled trials, with cost-effectiveness and impact on quality-of-life analysis, are urgently needed. They should also focus on specific populations and their comorbidities, since customizing telemedicine approaches is paramount to ensure success. Obstructive sleep apnea is a highly prevalent chronic condition and the most common of sleep-breathing disorders, and telemedicine and mHealth could play a pivotal role in the different phases of its management. In the future, using new devices capable of signal acquisition and analysis will refine obstructive sleep apnea diagnosis; even smartphones' built-in sensors could offer improved comfort and the possibility of home sleep monitoring. Continuous positive airway pressure titration could be performed with wireless devices, whose parameters can be changed remotely from sleep centers. Finally, the follow-up phase could be specially improved by telemedicine by using remote continuous positive airway-pressure data, self-management platforms, and mobile applications for patient feedback. Incorporating new procedures with novel technologies and sensors will probably change the process. Instead of replicating traditional visits, mHealth may provide shorter and more frequent assessments; alarm systems on the patients' devices could alert physicians or mobile applications with simple questionnaires may help on follow-up. With telemedicine, patients will not be treated in the same way.
\end{abstract}

Keywords: mHealth, telemedicine, obstructive sleep apnea, continuous positive airway pressure

\section{Introduction}

Telehealth $(\mathrm{TH})$ is the provision of health care remotely using telecommunications, including telephones, smartphones, and mobile wireless devices, with or without a video connection. ${ }^{1}$ However, at present the concept itself is broader. Indeed, Ambrosino et al explained that the following four concepts must be considered before using technology for follow-up or to improve treatment: 1) it should improve access and reduce cost; 2) it should be suitable for care of chronic conditions (including global health status); 3 ) it should maintain contact with a reference hospital; and 4) it should provide education. ${ }^{2}$

Sleep-disordered breathing (SDB), in terms of both patient characteristics and the processes applied, probably represents a clinical area were telemedicine could 
play a pivotal role. ${ }^{3}$ In obstructive sleep apnea (OSA), for example, there is scope for assistance in ensuring adequate treatment, including sleep hygiene and continuous positive airway pressure (CPAP) compliance, the latter of which is an essential component of effective treatment. With OSA and other SDB, it is also necessary to provide an optimal diagnosis procedure and follow-up, particularly during the first weeks of treatment. ${ }^{4}$

The American Academy of Sleep Medicine's Task Force on Sleep Telemedicine supports telemedicine as a means of advancing patient health by improving access to the expertise of certified sleep medicine specialists. ${ }^{5}$ Some publications have described the use of telemedicine for respiratory disease, congestive heart failure, and other chronic illnesses. ${ }^{6}$ However, few telemedicine applications have been designed and implemented to support the diagnosis and management of OSA, which is surprising, given that this is such a prevalent chronic disease for which novel social, health care, and economic strategies are urgently needed. ${ }^{3}$

CPAP is the optimal treatment for OSA, but it is underused by a significant number of patients. Reports indicate that only half of all patients remain compliant with CPAP by 3 months after initiating therapy, ${ }^{4}$ and it is well known that closer follow-up during the first weeks of treatment can improve compliance. ${ }^{7}$ Therefore, a major challenge for sleep specialists is optimizing patient compliance, especially when initiating treatment, yet overloaded sleep units have trouble providing such support because of a lack of financial resources. $^{8}$

$\mathrm{TH}$ has the potential to deliver effective and convenient care that can improve compliance and patient satisfaction, and reduce absenteeism to attend specialist sleep centers. ${ }^{9} \mathrm{We}$ thus performed a systematic review of the published literature on the role of telemedicine compared to routine face-to-face care for monitoring and improving outcomes in patients with OSA receiving CPAP therapy, with special consideration to phone calls, videoconferencing, e-mails, websites, mobile texting, and mobile applications. Since we believe compliance is affected by the first contact with diagnosis procedures and mainly by the first night of treatment (CPAP titration), both aspects are also reviewed.

\section{The role of telemedicine and mobile health when diagnosing SDB}

The widespread adoption and use of wireless technologies is changing the way patients with sleep disorders are being diagnosed, monitored, and treated. With this in mind, telemedicine-based strategies could be a major component in the development of a comprehensive and cost-effective solution for these aspects of common SDB, like OSA. ${ }^{10}$ Advances in mobile technology, and their applications in sleep health, are progressing to a level where physiological signal acquisition and analysis can be carried out by a smartphone's built-in sensors, offering improved comfort and the possibility of home sleep monitoring to patients with sleep disorders. ${ }^{11}$ We review the traditional diagnostic procedures and the present telemedicine tools and apps.

\section{Traditional OSA diagnosis}

Polysomnography (PSG) is still considered the medical gold standard for the diagnosis of OSA. However, it is an expensive, complex, and time-consuming test that often has long waiting lists, ${ }^{12}$ so there is a need to develop simplified ambulatory devices. ${ }^{13}$ Portable monitoring devices offer advantages compared with in-lab PSG, including time and resource efficiency, the possibility of home testing, lower costs, and compatibility with telemedicine. ${ }^{14}$ Studies have shown that portable sleep devices may be especially useful in patients with a high pretest probability for OSA. ${ }^{15,16}$ However, its applicability in patients with other comorbidities has been evaluated in few studies, and further research is needed to validate their use. ${ }^{17}$

\section{Diagnosis of OSA using telemedicine}

Some studies have investigated the role of telemedicine in novel diagnostic strategies for OSA. To this end, Bruyneel et al developed a telemonitoring system that could transmit physiological parameters in real time from portable PSG through an at-home wireless device to a remote sleep unit. ${ }^{18}$ In another study, a telematic system, which combined a teleconsultation system with the real-time transmission of parameters from respiratory polygraphy and automatic CPAP, was implemented for managing OSA. ${ }^{19}$ These studies indicate that telemedicine approaches could help to establish diagnostic and therapeutic strategies for OSA in a home setting. However, further to this, portable systems for the diagnosis and stratification of OSA were developed by AlMardini et $\mathrm{al}^{20}$ and Garde et $\mathrm{al}^{21}$ using the built-in sensors in smartphones together with external sensors. Physiological signals, including oxygen saturation $\left(\mathrm{SO}_{2}\right)$, body movement, respiratory effort, and pulse rate variability, were extracted and analyzed to determine the apnea-hypopnea and oxygen desaturation indexes. For patients with suspected OSA, these studies provided highly sensitive, specific, and accurate results compared with PSG. However, there has been 
no comprehensive validation or testing in a larger number of clinical patients to confirm the reliability and validity of the findings.

\section{OSA diagnosis using mobile health}

Mobile health (mHealth) is the use of mobile and wireless devices to improve health outcomes, health care services, and health research, and it includes the acquisition, processing, analysis, and transmission of health-related patient data. ${ }^{22}$ Currently, mobile platforms, such as smartphones and mobile devices, incorporate key features like advanced powerful computing, built-in sensors, such as accelerometers, microphones, and cameras, capacious memories, open operating systems, and wireless connectivity that allow medical support when and where it is needed by patients. These features have encouraged the development of apps that allow patients to assess sleep-related patterns in a home setting.

Here, we review apps that could help in OSA screening by recording physiological parameters (body motion, activity, audio, and $\mathrm{SO}_{2}$ ) using smartphones' built-in sensors coupled or not with external devices. Using the sleep-related features combined with clinically validated questionnaires, patients could be classified as either OSA or non-OSA. Other recent studies are summarized in Table 1.

\section{Movement and body position screening in sleep medicine}

One of the most common ways of assessing sleep-related parameters is through actigraphy, which can estimate waking/ sleeping states through the presence or absence of limb movements. ${ }^{23}$ Indeed, studies have found that actigraphy can be helpful for sleep research, because it tends to be less expensive and is more comfortable compared to PSG. ${ }^{24,25}$

Similarly, many sleep-related apps that register body position and movement using built-in accelerometers have been developed. Each app has its own algorithm to relate the amount of movement detected to specific waking/ sleeping states, and to estimate sleep patterns. Studies have suggested that such algorithms, which have been validated reporting high sensitivity and specificity, could be used in the future to advance sleep studies at home and in clinical sleep research. ${ }^{26,27}$ Currently, many apps available in Google Play and the Apple Store measure movement and waking/ sleeping parameters during sleep. Such apps as SleepBot, ${ }^{28}$ Sleep as Android, ${ }^{29}$ and Sleep Cycle ${ }^{30}$ calculate sleep quality by combining total sleep time and the amount of movement. However, most have not been validated by scientific studies.

Bhat et $\mathrm{al}^{31}$ compared a commercial accelerometer (UP by Jawbone) worn as a wristband coupled with an app (MotionX-24/7) against PSG testing and actigraphy (Actiwatch 2) in a clinical cohort of 78 children and adolescents with suspected SDB. The results showed no differences in the means of some standard sleep parameters among PSG, actigraphy, and accelerometry. However, the app underestimated sleep-onset latency and waking after sleep onset and overestimated total sleep time. Therefore, using this app in a clinical or research setting should be considered carefully. In another study, five commercial wearable wrist-worn devices used for measuring

Table I Recent research using smartphones for OSA screening

\begin{tabular}{|c|c|c|c|c|}
\hline Recorded parameters & Reference & Sensors & Signals & Summary \\
\hline \multirow[t]{2}{*}{$\begin{array}{l}\text { Movement and body } \\
\text { position }\end{array}$} & Zhu et $\mathrm{al}^{33}$ & Actigraph & $\begin{array}{l}\text { Motion intensity, } \\
\text { acceleration, respiratory } \\
\text { effort }\end{array}$ & $\begin{array}{l}\text { A portable system integrating microsensors with } \\
\text { mobile devices for monitoring and diagnosing OSA } \\
\text { in a home setting was developed. }\end{array}$ \\
\hline & $\begin{array}{l}\text { Hummel } \\
\text { et } \mathrm{al}^{34}\end{array}$ & & & $\begin{array}{l}\text { Head actigraphy showed good performance } \\
\text { detecting sleeping/waking status. }\end{array}$ \\
\hline \multirow[t]{2}{*}{$\begin{array}{l}\text { Snoring and } \\
\text { breath sound }\end{array}$} & Koo et $\mathrm{al}^{35}$ & Microphone & Audio & $\begin{array}{l}\text { Acoustic analysis of snoring sound recorded by a } \\
\text { smartphone could be a useful screening test for the } \\
\text { prediction of occlusion sites in OSA patients. }\end{array}$ \\
\hline & $\begin{array}{l}\text { Nandakumar } \\
\text { et } \mathrm{al}^{36}\end{array}$ & & & $\begin{array}{l}\text { Smartphone used as a sonar system that emits } \\
\text { frequency-modulated sound signals to extract chest } \\
\text { movements and identify OSA events showed a high } \\
\text { correlation with PSG. }\end{array}$ \\
\hline \multirow[t]{2}{*}{ Oximetry signals } & Garde et $\mathrm{al}^{21}$ & Oximeter & $\mathrm{SpO}_{2}$, pulse rate variability & $\begin{array}{l}\mathrm{SpO}_{2} \text { combined with pulse rate variability could help } \\
\text { to detect OSA events used as a portable device } \\
\text { integrated into a smartphone. }\end{array}$ \\
\hline & Behar et $\mathrm{al}^{37}$ & & & $\begin{array}{l}\text { An app for OSA screening using recorded } \mathrm{SpO}_{2} \\
\text { combined with movement, snoring, and body } \\
\text { position and a questionnaire were developed. }\end{array}$ \\
\hline
\end{tabular}

Abbreviations: OSA, obstructive sleep apnea; PSG, polysomnography; $\mathrm{SpO}_{2}$, peripheral oxygen saturation. 
sleep features together with research-based actigraphy were compared with PSG, showing no differences among devices and a strong correlation with total sleep time recorded by PSG. ${ }^{32}$

There is a known correlation between the severity of apneic events and body position during sleep. The effect of body position on OSA is such that severity increases when patients sleep in the supine position. ${ }^{38,39}$ Apps like SomnoPose ${ }^{40}$ can monitor accelerometer data from a smartphone to determine body position, and emit a smart alarm when the patient is on their back.

\section{Audio recording: snoring and breath}

Breath and snoring during sleep could provide essential information about breathing patterns and flow limitation. Logically, an overnight audio recording of a patient could be a preliminary tool for discriminating between patients with different severities of OSA and those who are simple (nonOSA) snorers. Using signal processing and pattern recognition algorithms, several studies have addressed the detection of snoring and breathing sounds during sleep. An algorithm for analysis and recording of snoring sounds using a smartphone was implemented by Nakano et al, ${ }^{41}$ and their results showed a high correlation between the snoring time measured by the smartphone and that measured during the PSG test. However, the authors argued that use of this approach was unproven in a noisy home environment, and that further investigation was needed. Apps like Snoring Detector Pro ${ }^{42}$ can detect snoring and instruct patients to adjust their sleeping position with light and short pulses on a smart watch.

Although audio offers a potential non-contact alternative, there are multiple parameters in audio acquisition that are relevant to audio quality, including frequency response of the smartphone's sound card, format of the recorded audio file, quality of the microphone, and position of the microphone in relation to the subject. ${ }^{43}$ Several authors have evaluated the usefulness of apps for detecting sleep-related parameters. Stippig et $\mathrm{al}^{44}$ compared some apps for monitoring and recording sleep sounds, concluding that the tested apps were not sufficiently accurate to replace the standard diagnostic methods. Ong et $\mathrm{al}^{45}$ also reviewed several features provided by sleep analysis apps to record sounds during sleep, and concluded that physicians have to be aware of the most common apps' features and limitations to counsel patients properly when they inquire about them.

\section{Oximetry signals}

Peripheral $\mathrm{SO}_{2}\left(\mathrm{SpO}_{2}\right)$ level is a good complementary measurement for identifying apneic events during sleep testing.
Pulse oximetry is a noninvasive method of measuring $\mathrm{SpO}_{2}$ that records tissue changes using a photoplethysmographic signal. ${ }^{46}$ Currently, many apps are also available for pulseoximetry assessment. These include Pulse Oximeter ${ }^{47}$ and Instant Heart Rate, ${ }^{48}$ which can provide information on both heart rate and $\mathrm{SO}_{2}$, using just the light source and camera of the smartphone (called reflective pulse oximetry), without the need for an external device. However, they have not been validated by scientific studies. Overall, there is a lack of literature that rigorously evaluates the impact of mHealth on sleep medicine, and new methods or instruments are needed to assess the efficacy of apps in sleep medicine.

\section{Telemedicine-based support during CPAP treatment}

Several studies have reported that a main predictive factor for long-term CPAP compliance is patient adherence in the first weeks of treatment. To improve it, support and followup during this period must be tight. Telemedicine strategies seem to be appropriate to offer this kind of assistance, since long waiting lists and overweighed health care services make difficult such support. Therefore, if we wish to improve patient adherence, titration, training, and follow-up, it must be complemented with adequate education about OSA, CPAP, and mask use, and personalized depending on the patient's characteristics, so that the most appropriate cases are treated in the sleep unit with specialized technical support, while less complex cases can be titrated or followed by home-based settings. ${ }^{3}$ We review the available evidence regarding different telemedicine approaches mainly targeting training, and adherence to accomplish adequate long-term CPAP compliance.

\section{Coaching phone calls}

Chervin et $\mathrm{al}^{7}$ performed one of the first telemedicine-focused randomized controlled trials (RCTs) among 33 subjects with interventions that were designed to improve compliance. One group received weekly phone calls to uncover any problems and encourage CPAP use, a second group received written information about OSA and the importance of regular CPAP use, and a third group served as controls (no information). In this RCT, the first two interventions were associated with improved CPAP compliance, and this was particularly strong when the intervention occurred during the first month of CPAP treatment. However, some 15 years later, compliance was still estimated to be below $50 \%-70 \%$, which motivated Leseux et $\mathrm{al}^{49}$ to evaluate the feasibility of an educational intervention (EI) in 66 patients with OSA receiving CPAP compared with patients receiving standard care. The EI 
consisted of five educational sessions delivered by phone in the first 3 months after treatment initiation. Although there were no statistical differences, CPAP compliance at 3 months was 54 minutes more in the EI group compared with the control group, and this difference became statistically significant by 6 months. Although both studies produced positive results, the small sample sizes should be taken into consideration.

\section{Interactive voice response (IVR) systems}

Initial forays into the use of telecommunication follow-up included the use of IVR systems, which involves a telephone mechanism to survey patients. IVR systems can automate phone calls to patients and ask a series of questions (eg, "Are you using CPAP?"), formatted in a way that patients can answer by pushing the telephone keypad (eg, "Press 1 for yes, press 2 for no"). ${ }^{50}$ DeMolles et al ${ }^{51}$ performed a pilot study to test this function among 30 patients being started on CPAP. They included questions regarding CPAP use, such as "How many days this week did you use your CPAP?" If the patient's answers were suboptimal, based on predetermined thresholds, the system would ask questions aimed at identifying predefined problems and then provide brief education and reinforcement. The study concluded that after 2 months, patients with OSA who received automated education with a concurrent counseling program had better CPAP adherence and better control of OSA symptoms than those receiving usual care alone. This pilot trial was followed by an RCT by Sparrow et $\mathrm{al}^{52}$ that included 250 patients and a longer follow-up. This confirmed that after a year, this system improved CPAP adherence and was associated with improved functional status and fewer depressive symptoms. The use of IVR systems as a telemedicine strategy seems to be very useful for collecting patient feedback; however, researchers have mentioned that it creates data overload when following large populations.

\section{Wireless telemonitoring of treatment compliance and efficacy}

The impact of remote monitoring is particularly relevant, given the wireless capabilities of new-generation CPAP devices. Various CPAP modems compatible with Ethernet cables, home Wi-Fi networks, or Bluetooth connections to transfer data have been developed. ${ }^{50}$

In 2007, Stepnowsky et $\mathrm{al}^{53}$ performed a pilot study to determine whether wireless telemonitoring of CPAP data improved CPAP compliance. They randomized 45 patients into remote monitoring or usual care groups. With the remote monitoring protocol, sleep specialists could review hours of
CPAP use, mask leak, and the apnea-hypopnea index, while the usual care group received only a telephone call after 1 week and a follow-up office visit after 1 month. Although similar compliance was reported in both groups, the intervention group indicated that they were significantly more likely to continue using CPAP compared with the usual-care group. In a similar study carried out by Fox et al, 39 patients were randomized to telemedicine and 36 patients to standard care. ${ }^{54}$ Remote monitoring resulted in a near doubling of CPAP use at 3 months (191 vs 105 minutes/night). In this study, CPAP data were monitored daily and patients contacted if suboptimal use or other problems were indicated. However, both groups still reported low overall CPAP compliance.

More recently, Anttalainen et $\mathrm{al}^{55}$ have performed a study showing that telemonitoring could improve adherence to CPAP and save nursing time. After CPAP titration, 111 consecutive patients with OSA were randomized to usual care $(n=61)$ or telemonitoring $(\mathrm{n}=50)$ protocols, using fixed-pressure CPAP with and without wireless telemonitoring, respectively. The following end points were used: CPAP use $>4$ hours/day, mask leak, apnea-hypopnea index $<5$ per hour, and nursing time (including phone calls and visits). Their results showed that there were significant differences in nursing time between the follow-up protocols, without compromising the short- or long-term effectiveness of treatment. Although the availability of objective and diverse data about CPAP provides useful and actionable information, such wireless telemonitoring suffers from the same limitation as IVR, in that it leads to data overload when trying to manage a large patient population. ${ }^{50}$

\section{Videoconference}

Telemedicine may allow greater access to care; however, its effect on patient satisfaction and treatment adherence is not fully understood, despite some studies suggesting good acceptance and compliance. For example, Parikh et $\mathrm{al}^{56}$ compared patient satisfaction and CPAP adherence based on videoconference $(n=34)$ with face-to-face $(n=56)$ specialist consultations, but showed similar compliance and satisfaction in both groups. In another study, Isetta et $\mathrm{al}^{10}$ analyzed the satisfaction of 50 patients with OSA with a physician-based teleconsultation (videoconference), showing that $>95 \%$ of patients were satisfied and that $66 \%$ would be happy to replace their CPAP follow-up visits with teleconsultations. Interestingly, they also included 40 patients with OSA who were scheduled to receive CPAP training and randomized them to receive usual face-to-face training or training via videoconference. After the session, participants were evaluated blindly on what they learned about OSA and mask placement. The 
authors reported that patients trained by videoconference demonstrated the same knowledge about OSA and the same performance on practical skills (mask and headgear placement and leak avoidance) as the face-to-face group.

We believe that videoconferencing is also a promising tool for obtaining valuable information from patients in a face-to-face consultation. A major limitation, though, is that videoconferencing requires access to a fast Internet connection to take place without interruption. In addition, its use on smartphones can generate high levels of data consumption (cost to the patient) if not used with Wi-Fi networks.

\section{Combined approaches for CPAP telemonitoring}

A couple of very recent studies have gone beyond assessing single interventions, and instead designed RCTs that mixed different telemedicine strategies to improve CPAP use and efficacy. In their research, Munafo et $\mathrm{al}^{57}$ randomized 58 patients starting CPAP treatment to TH management and 64 to standard care, and compared compliance rates and health care utilization. All participants received standard CPAP education and setup, but the TH group also received wireless monitoring, with an IVR system that used an automated series of text messages and/or emails triggered by preset conditions acquired by wireless monitoring. The standard care group received only scheduled calls on days $1,7,14$, and 30 . There were no statistically significant differences in daily CPAP use, efficacy, or OSA symptoms, though all trends favored the TH group. There was also a significant reduction in the coaching time required per patient in the TH group. In another RCT, 556 patients with OSA were randomized to 1) usual care, 2) usual care plus web education, 3) usual care plus automated follow-up, or 4) all provision (ie, usual care plus web education plus automated follow-up). ${ }^{58}$ After 3 months, the authors concluded that automated telemonitoring follow-up but not web education improved CPAP compliance.

\section{Self-management CPAP follow-up: platforms and mobile applications}

Today, the ability of CPAP devices to transmit data automatically is not only useful when accessed by sleep specialists. Based on the ideas of self-quantification and self-management, these data encourage management autonomy and have been shown to improve CPAP adherence. ${ }^{50}$

\section{Platforms}

MyCPAP was the first CPAP self-management platform to use wirelessly transmitted CPAP data. ${ }^{59}$ It basically used a website with the following elements: 1) CPAP-use and efficacy information displayed on charts, 2) surveys with questions related to symptoms, 3 ) educational information about OSA and CPAP, and 4) a user manual and troubleshooting guide for CPAP. Using this platform, an RCT conducted to analyze compliance with CPAP among 241 patients showed that those in the MyCPAP group had significantly improved CPAP use compared with controls at 2 months (4.1 vs 3.4 hours/night). Kuna et $\mathrm{al}^{60}$ followed this with an RCT of 138 patients randomized to either usual care alone or usual care plus access to CPAP data via an online portal. Those with online access had significantly better CPAP use per night (about 6 hours) compared with the usual-care group (4.7 hours) after 3 months. Therefore, giving patients access to their own data could help improve compliance.

\section{Apps}

Mobile phones seem particularly suited for reaching patients, so it is perhaps unsurprising that mHealth products have been assessed for their potential to improve health outcomes. Indeed, the volume and variety of apps are already immense, and this is estimated to keep growing in coming years. ${ }^{61} \mathrm{We}$ have seen that there is significant potential for assessing sleep quality, helping with the diagnosis of OSA, and providing lower-cost CPAP follow-up. However, there are only a few properly tested and validated apps. One such app, SleepMapper, combines a mobile application and website from Philips Respironics to provide patients with data on their individual adherence, therapy, and OSA events, together with other tools and techniques for dealing with their therapy. Hardy et $\mathrm{al}^{62}$ analyzed a retrospective group of $\sim 15,000$ patients from the Philips Respironics EncoreAnywhere database who were using the SleepMapper app and website. They showed improved adherence rates compared to standard care. SleepMapper also helped those patients who struggled early with therapy compared with patients who did not use the app. In keeping with these findings, Isetta et $\mathrm{al}^{8}$ designed, developed, and tested a novel App called AppNea, which aimed to promote self-monitoring of CPAP therapy in patients with OSA. They included 34 patients with diagnosed OSA, and asked them to use AppNea for 6 weeks while receiving CPAP treatment. The app used a daily questionnaire about CPAP use and lifestyle, and showed the patient their general compliance with treatment. At the end of the intervention, it was shown that mean CPAP compliance exceeded 5 hours and that $91 \%$ of patients were satisfied with the use of AppNea. This evidence suggests that app-based interventions are at least feasible. Studies are summarized in Table 2. 
Table 2 Telemedicine approaches to improve CPAP follow-up

\begin{tabular}{|c|c|c|c|}
\hline Reference & Subjects (n) & Study length & Summary \\
\hline \multicolumn{4}{|l|}{ Phone call } \\
\hline Chervin et $\mathrm{al}^{7}$ & 33 & I month & $\begin{array}{l}\text { Interventions significantly improved CPAP use in the first month of } \\
\text { CPAP treatment. }\end{array}$ \\
\hline Leseux et al ${ }^{49}$ & 101 & 6 months & Higher adherence to CPAP in the intervention group. \\
\hline \multicolumn{4}{|c|}{ Interactive voice response } \\
\hline DeMolles et al ${ }^{51}$ & 30 & 2 months & $\begin{array}{l}\text { Better CPAP adherence and control of symptoms in the } \\
\text { intervention group. }\end{array}$ \\
\hline Sparrow et al ${ }^{52}$ & 250 & 12 months & $\begin{array}{l}\text { Improved CPAP adherence and functional status, with fewer } \\
\text { depressive symptoms. }\end{array}$ \\
\hline \multicolumn{4}{|c|}{ Wireless telemonitoring } \\
\hline Stepnowsky et al ${ }^{53}$ & 45 & 2 months & $\begin{array}{l}\text { Similar compliance in both groups. The intervention group had a } \\
\text { significantly higher likelihood of continuing using CPAP. }\end{array}$ \\
\hline Fox et $\mathrm{al}^{54}$ & 75 & 3 months & $\begin{array}{l}\text { Intervention group nearly doubled CPAP use. However, both } \\
\text { groups showed low adherence. }\end{array}$ \\
\hline Anttalainen et a ${ }^{55}$ & 111 & 12 months & $\begin{array}{l}\text { Significant differences in nursing time, with similar treatment } \\
\text { effectiveness. }\end{array}$ \\
\hline \multicolumn{4}{|l|}{ Videoconference } \\
\hline Parikh et al ${ }^{56}$ & 90 & 2 weeks & $\begin{array}{l}\text { Similar compliance and satisfaction was reported in both groups, } \\
\text { but study length was quite short. }\end{array}$ \\
\hline \multirow[t]{2}{*}{ Isetta et al $\left.\right|^{10}$} & l) 50 & I) I visit & I. Patients were highly satisfied with a physician teleconsultation. \\
\hline & 2) 40 & 2) I visit & $\begin{array}{l}\text { 2. CPAP training via videoconference proved to be as effective as } \\
\text { face-to-face training. }\end{array}$ \\
\hline \multicolumn{4}{|l|}{ Web platform } \\
\hline Stepnowsky et al ${ }^{59}$ & 241 & 2 months & $\begin{array}{l}\text { Patients with access to MyCPAP platform to self-monitor CPAP use } \\
\text { showed significantly improved adherence. }\end{array}$ \\
\hline Kuna et al ${ }^{60}$ & 138 & 3 months & $\begin{array}{l}\text { Patients with access to a self-monitoring platform had significantly } \\
\text { improved CPAP adherence. }\end{array}$ \\
\hline \multicolumn{4}{|c|}{ Mobile application } \\
\hline Hardy et $\mathrm{al}^{62}$ & 15,000 & 3 months & $\begin{array}{l}\text { Patients with the mobile app and website showed improved } \\
\text { adherence compared with standard care. }\end{array}$ \\
\hline Isetta et al ${ }^{8}$ & 34 & 6 weeks & $\begin{array}{l}\text { Patients who used the AppNea app showed adequate CPAP } \\
\text { compliance and high satisfaction, suggesting the app-based } \\
\text { intervention was feasible. }\end{array}$ \\
\hline \multicolumn{4}{|c|}{ Combined telemedicine approaches } \\
\hline Munafo et $\mathrm{al}^{57}$ & 122 & I month & $\begin{array}{l}\text { No differences for CPAP use or efficacy, although all trends favored } \\
\text { the telehealth group, in which the coaching time was reduced. }\end{array}$ \\
\hline Hwang et al ${ }^{58}$ & 556 & 3 months & $\begin{array}{l}\text { Telemonitoring follow-up but not web education improved CPAP } \\
\text { compliance. }\end{array}$ \\
\hline
\end{tabular}

Abbreviation: CPAP, continuous positive airway pressure.

\section{Telemedicine support in non-CPAP treatment}

OSA is a common disorder that has all the characteristics of a chronic condition, and as such should be approached as a disease requiring long-term and multidisciplinary management of treatments and problems, including residual symptoms, deficits, and comorbidities. Also, many patients with OSA have modifiable lifestyle factors that contribute to their disease, which could be improved by appropriate intervention. General education on the impact of weight loss, sleep position, alcohol avoidance, risk factor modification, and medication effects should be provided. Patient education should also be delivered optimally as part of a multidisciplinary chronic disease-management team that includes the sleep physician, the referring provider, and any allied health care providers. ${ }^{63,64}$ Several publications have reported positive results using telemedicine to support home monitoring of patients with chronic heart failure, respiratory disease, diabetes, and other chronic illnesses. They have also been shown to improve compliance with treatment and to instigate behavior changes, such as smoking cessation, via telemedicine interventions (TIs). ${ }^{6,65}$

\section{Cost-effectiveness of telemedicine in OSA}

Recent reviews of the literature suggest that there is a lack of solid evidence on the cost-effectiveness of eHealth and mHealth systems. Some but not all cost-effectiveness studies show that telemedicine can reduce costs. Among the main 
limitations of any economic evaluation of telemedicine is the absence of quality data and appropriate measures; indeed, most studies have entirely equated benefits with cost savings, with no analysis of the benefits to patients. There is a need for RCTs with larger samples that compare different telemedicine scenarios if we are to assess the viability and effectiveness of telemedicine properly. ${ }^{66}$

\section{Cost-effectiveness in OSA diagnosis}

Recently, portable sleep-recording devices have become accepted as an alternative to PSG for diagnosing OSA in patients with a high pretest probability of the disorder. ${ }^{67,68}$ Bruyneel and Ninane ${ }^{69}$ reviewed the available evidence for home PSG (H-PSG) from six prospective randomized crossover studies comparing H-PSG to in-lab PSG. This analysis showed that H-PSG was suitable for complete sleep evaluation, that it was accurate for OSA diagnosis, and that the failure rate was low, despite the lack of supervision. It was also suggested that H-PSG might reduce costs, but it was also mentioned that cost-effectiveness analyses were not yet available.

Masa et $\mathrm{al}^{70}$ compared the costs incurred in home respiratory polygraphy and in-lab PSG using device transportation and telematic transmission of data. They found that both having devices moved by a transportation company and telematically sending raw data proved cost-effective and equally beneficial. This finding opens the possibility of its application among patients who inhabit places distant from the hospital or those with limited mobility.

\section{Cost-effectiveness of CPAP treatment and follow-up}

Concerning follow-up for OSA and CPAP, previous evidence supports the use of TIs designed to improve compliance with treatment. DeMolles et al and Stepnowsky et al ${ }^{51,53}$ conducted studies where telemonitoring was as effective as usual care in achieving CPAP adherence and efficacy, but economic efficiency and labor requirements were not addressed. Moreover, Fox et $\mathrm{al}^{54}$ randomized 75 patients in a 3-month study comparing usual care with a web-based telemonitoring application, and although adherence was improved in the TI group, on average more time was required to manage patients in the TI group. The authors postulated that the overall magnitude of this extra time was fairly minor (1 hour per patient), and believed it would be justified by the improved adherence.

Isetta et $\mathrm{al}^{9}$ performed a unicenter RCT providing evidence that a telemedicine-based strategy for the follow-up of CPAP treatment in patients with OSA was as effective as standard hospital-based care in terms of CPAP compliance and symptom improvement, with comparable side effects and satisfaction rates. The telemedicine-based strategy had lower total costs, due to savings in mobility and less lost productivity (indirect costs).

Recently, Munafo et $\mathrm{al}^{57}$ conducted a multicenter RCT where TI was associated with excellent adherence to CPAP therapy and significantly reduced the amount of hospital care professional time that was needed to achieve adherence and efficacy comparable to the usual care model. They speculated that the decrease in resources used in the TI group could largely be attributed to a marked reduction in the requirement for hospital care professionals to review adherence data manually, identify patients at risk, and provide coaching. Instead, automated notifications were delivered to the patient and their care provider. The reduction in labor required in the TI group was especially evident in the savings associated with coaching patients who reached adherence within the first 30 days. The TI program did not require any additional labor if the patient was responding well to CPAP therapy. In contrast, the usual care model required intensive labor investment, particularly during the first month. They concluded that whether these benefits translate into better cost-effectiveness remains to be determined.

Therefore, we conclude that results for cost-effectiveness are highly variable, with most of them from single-center studies where CPAP compliance remained low and sample sizes were small. Further well-designed studies that include cost-effectiveness analyses are needed to determine what the true benefit of telemedicine in this area is.

\section{Conclusion}

Rapid advances in technology, combined with the high prevalence of SDB and the increased demand for procedures, have encouraged a widespread interest in TH technologies. At present, telemedicine seems to offer credible solutions for managing the major health care challenges facing our society, such as the need to treat an aging population and the increased health care costs when managing chronic disease. Publications have shown benefits from using telemedicine in the management of several diseases, but that these benefits can be controversial when applied to the clinical arena, and that the interventions may not be cost-effective.

Of course, telemedicine is already here, and evidence abounds that a "tipping point" in TH is nearing. In fact, it is probable that rapid technological advances will in one way or another lead to a dramatic overhaul in the organization of academic and health systems. Although a networked working structure is a basic element of any health care system, the roles of the various health care professionals (specialists, 
family physicians, and nurses, among others) will undoubtedly change with time as new relations are formed between physicians, or between physicians and patients, in light of new procedures and methods of follow-up. Many advances will probably be linked to the Internet, smartphones, new sensors, or other devices that are available. Another example is that TH may not only change and facilitate the diagnostic process and associated procedures but may also change the very nature of the patient "visit". Indeed, TH does not need to replicate the traditional office; instead of the highly structured in-clinic visits, it may be possible to use shorter and more frequent assessments via multiple communication methods.

Despite the many possibilities, most of which will probably be implemented over time, caution is needed before they are transferred to the clinical arena. In an excellent invited commentary, Wilson and $\mathrm{Cram}^{71}$ argued that we need a better understanding of the critical factors (relating to the patient, the physician, the health care system, and the proposed $\mathrm{TH}$ program) that predict success if we are to target our interventions to those patients who are most likely to benefit. We must also have an awareness of what outcomes are appropriate for TH programs to affect. While awaiting answers to these questions, we advise that funders and physicians move slowly when implementing TH programs on a wide scale. It is our view that telemedicine is suitable for implementation in several conditions, but that the most important factors for successful outcomes are probably twofold. 1) It is important that we customize provision for specific patient groups, procedures, training, and health systems. 2) Physicians, other health care professionals, administration staff, and engineers must work in collaboration. Only when these criteria are met will we be able to ensure the success of an appropriate telemedicine application.

\section{Acknowledgments}

The authors thank Ramon Farré and Marta Torres for reviewing the final version of the manuscript. This work was supported by the Spanish Ministry of Economy and Competitiveness - Instituto de Salud Carlos IIIFIS (PI14/00416), SEPAR, and SOCAP.

\section{Disclosure}

The authors report no conflicts of interest in this work.

\section{References}

1. Dorsey ER, Topol EJ. State of telehealth. N Engl J Med. 2016;375(2): 154-161.

2. Ambrosino N, Vitacca M, Dreher M, et al. Tele-monitoring of ventilatordependent patients: a European Respiratory Society statement. Eur Respir J. 2016;48(3):648-663.
3. Isetta V, Ruiz M, Farré R, Montserrat JM. Supporting patients receiving CPAP treatment: the role of training and telemedicine. In: Barbé F, Pépin JL, editors. Obstructive Sleep Apnoea. Lausanne, Switzerland: European Respiratory Society; 2015:280-292.

4. Kribbs NB, Pack AI, Kline LR, et al. Objective measurement of patterns of nasal CPAP use by patients with obstructive sleep apnea. Am Rev Respir Dis. 1993;147(4):887-895.

5. Singh J, Badr MS, Diebert W, et al. American Academy of Sleep Medicine (AASM) position paper for the use of telemedicine for the diagnosis and treatment of sleep disorders. J Clin Sleep Med. 2015;11(10): 1187-1198.

6. Paré G, Moqadem K, Pineau G, St-Hilaire C. Clinical effects of home telemonitoring in the context of diabetes, asthma, heart failure and hypertension: a systematic review. J Med Internet Res. 2010;12(2):e21.

7. Chervin RD, Theut S, Bassetti C, Aldrich MS. Compliance with nasal CPAP can be improved by simple interventions. Sleep. 1997;20(4): 284-289.

8. Isetta V, Torres M, González K, et al. A new mHealth application to support treatment of sleep apnoea patients. J Telemed Telecare. Epub 2015 Dec 15.

9. Isetta V, Negrín MA, Monasterio C, et al. A Bayesian cost-effectiveness analysis of a telemedicine-based strategy for the management of sleep apnoea: a multicentre randomised controlled trial. Thorax. 2015;70(11):1054-1061.

10. Isetta $\mathrm{V}$, León $\mathrm{C}$, Torres $\mathrm{M}$, et al. Telemedicine-based approach for obstructive sleep apnea management: building evidence. J Med Internet Res. 2014;16(2):1-12.

11. Jalali L, Bigelow P. Current status and future trends of wireless and mobile health technologies in sleep medicine: insomnia case study. In: Adibi S, editor. Mobile Health: A Technology Road Map. Heidelberg: Springer; 2015:129-144.

12. Kushida CA, Littner MR, Morgenthaler T, et al. Practice parameters for the indications for polysomnography and related procedures: an update for 2005. Sleep. 2005;28(4):499-521.

13. Flemons WW, Littner MR, Rowley JA, et al. Home diagnosis of sleep apnea: a systematic review of the literature: an evidence review cosponsored by the American Academy of Sleep Medicine, the American College of Chest Physicians, and the American Thoracic Society. Chest. 2003;124(4):1543-1579.

14. Oliveira MG, Nery LE, Santos-Silva R, et al. Is portable monitoring accurate in the diagnosis of obstructive sleep apnea syndrome in chronic pulmonary obstructive disease? Sleep Med. 2016;13(8): 1033-1038.

15. Collop NA, Anderson WM, Boehlecke B, et al. Clinical guidelines for the use of unattended portable monitors in the diagnosis of obstructive sleep apnea in adult patients. J Clin Sleep Med. 2007;3(7):737-747.

16. Mohsenin V. Portable monitoring for obstructive sleep apnea: the horse is out of the barn-avoiding pitfalls. Am J Med. 2013;126(4):e1-e3.

17. Qaseem A, Dallas P, Owens DK, Starkey M, Holty JE, Shekelle P. Diagnosis of obstructive sleep apnea in adults: a clinical practice guideline from the American College of Physicians. Ann Intern Med. 2014; 161(3):210-220.

18. Bruyneel M, van den Broecke S, Libert W, Ninane V. Real-time attended home-polysomnography with telematic data transmission. Int $J$ Med Inform. 2016;82(8):696-701.

19. Coma-del-Corral MJ, Alonso-Alvarez ML, Allende M, et al. Reliability of telemedicine in the diagnosis and treatment of sleep apnea syndrome. Telemed J E Health. 2013;19(1):7-12.

20. Al-Mardini M, Aloul F, Sagahyroon A, Al-Husseini L. Classifying obstructive sleep apnea using smartphones. J Biomed Inform. 2014; 52:251-259.

21. Garde A, Dehkordi P, Wensley D, Ansermino JM, Dumont GA. Pulse oximetry recorded from the Phone Oximeter for detection of obstructive sleep apnea events with and without oxygen desaturation in children. Conf Proc IEEE Eng Med Biol Soc. 2015;2015:7692-7695.

22. Kay M. mHealth: New Horizons for Health Through Mobile Technologies. Geneva: World Health Organization; 2011. 
23. Roebuck A, Monasterio V, Gederi E, et al. A review of signals used in sleep analysis. Physiol Meas. 2014;35(1):R1-R57.

24. Sadeh A. The role and validity of actigraphy in sleep medicine: an update. Sleep Med Rev. 2016;15(4):259-267.

25. Gautam A, Naik VS, Gupta A, Sharma SK, Sriram K. An [sic] smartphone-based algorithm to measure and model quantity of sleep. Poster presented at: 7th International Conference on Communication Systems and Networks; January 6-10, 2015; Bangalore, India.

26. Nakazaki K, Kitamura S, Motomura Y, et al. Validity of an algorithm for determining sleep/wake states using a new actigraph. $J$ Physiol Anthropol. 2014;33:31.

27. Tilmanne J, Urbain J, Kothare MV, Wouwer AV, Kothare SV. Algorithms for sleep-wake identification using actigraphy: a comparative study and new results. J Sleep Res. 2009;18(1):85-98.

28. SleepBot [website on the Internet]. Available from: http://www.mysleepbot.com. Accessed December 23, 2016.

29. Sleep as Android [website on the Internet]. Available from: http://sleep. urbandroid.org. Accessed December 23, 2016.

30. Sleep Cycle alarm clock [website on the Internet]. Available from: http:// www.sleepcycle.com. Accessed December 23, 2016.

31. Bhat S, Ferraris A, Gupta D, et al. Is there a clinical role for smartphone sleep apps? Comparison of sleep cycle detection by a smartphone application to polysomnography. J Clin sleep Med. 2015;11(7):709-715.

32. Mantua J, Gravel N, Spencer RM. Reliability of sleep measures from four personal health monitoring devices compared to research-based actigraphy and polysomnography. Sensors (Basel). 2016;16(5):E646.

33. Zhu R, Cao Z, Que R. Integration of micro sensors with mobile devices for monitoring vital signs of sleep apnea patients. Poster presented at: 9th IEEE International Conference on Nano/Micro Engineered and Molecular Systems; April 13-16, 2014; Honolulu, HI.

34. Hummel R, Bradley TD, Fernie GR, Chang SJ, Alshaer H. Estimation of sleep status in sleep apnea patients using a novel head actigraphy technique. Conf Proc IEEE Eng Med Biol Soc. 2015;2015:5416-5419.

35. Koo SK, Kwon SB, Kim YJ, Moon JI, Kim YJ, Jung SH. Acoustic analysis of snoring sounds recorded with a smartphone according to obstructive site in OSAS patients. Eur Arch Otorhinolaryngol. Epub 2016 Oct 5 .

36. Nandakumar R, Gollakota N, Watson N. Contactless sleep apnea detection on smartphones. Poster presented at: 13th Annual International Conference on Mobile Systems, Applications, and Services; May 18-22, 2015; Florence, Italy.

37. Behar J, Roebuck A, Shahid M, et al. SleepAp: an automated obstructive sleep apnoea screening application for smartphones. IEEE J Biomed Health Inform. 2015;19(1):325-331.

38. Oksenberg A, Gadoth N. Are we missing a simple treatment for most adult sleep apnea patients? The avoidance of the supine sleep position. J Sleep Res. 2014;23(2):204-210.

39. Chen WC, Lee LA, Chen NH, et al. Treatment of snoring with positional therapy in patients with positional obstructive sleep apnea syndrome. Sci Rep. 2015;5:18188.

40. Proximal Box Software [website on the Internet]. SomnoPose sleep position monitor. Available from: www.proximalbox.com. Accessed December 23, 2016

41. Nakano H, Hirayama K, Sadamitsu Y, et al. Monitoring sound to quantify snoring and sleep apnea severity using a smartphone: proof of concept. J Clin Sleep Med. 2014;10(1):73-78.

42. Braci [website on the Internet]. Snore Detector Pro. Available from: http://www.braci.co/snore-detector. Accessed December 23, 2016.

43. Behar J, Roebuck A, Domingos JS, Gederi E, Clifford GD. A review of current sleep screening applications for smartphones. Physiol Meas. 2013;34(7):R29-R46.

44. Stippig A, Hübers U, Emerich M. Apps in sleep medicine. Sleep Breath. 2015;19(1):411-417.

45. Ong AA, Gillespie MB. Overview of smartphone applications for sleep analysis. World J Otorhinolaryngol Neck Surg. 2016;2(1):45-49.

46. Fietze I, Dingli K, Diefenbach K, et al. Night-to-night variation of the oxygen desaturation index in sleep apnoea syndrome. Eur Respir J. 2004;24(6):987-993.
47. DigiDoc Technologies. Pulse Oximeter. Available from: http://www. digidoctech.no. Accessed December 23, 2016.

48. Azumio. Instant Heart Rate. Available from: http://www.azumio.com/s/ instantheartrate/index.html. Accessed December 23, 2016.

49. Leseux L, Rossin N, Sedkaoui K, et al. Faisabilité du " coaching » téléphonique dans l'appareillage du syndrome d'apnée du sommeil. Coaching téléphonique et SAS [Education of patients with sleep apnea syndrome: feasibility of a phone coaching procedure - phone-coaching and SAS]. Rev Mal Respir. 2012;29(1):40-46. French.

50. Hwang D. Monitoring progress and adherence with positive airway pressure therapy for obstructive sleep apnea. Sleep Med Clin. 2016;11(2):161-171.

51. DeMolles DA, Sparrow D, Gottlieb DJ, Friedman R. A pilot trial of a telecommunications system in sleep apnea management. Med Care. 2004;42(8):764-769.

52. Sparrow D, Aloia M, DeMolles DA, Gottlieb DJ. A telemedicine intervention to improve adherence to continuous positive airway pressure: a randomised controlled trial. Thorax. 2010;65(12):1061-1066.

53. Stepnowsky CJ, Palau JJ, Marler MR, Gifford AL. Pilot randomized trial of the effect of wireless telemonitoring on compliance and treatment efficacy in obstructive sleep apnea. J Med Internet Res. 2007;9(2):e14.

54. Fox N, Hirsch-Allen AJ, Goodfellow E, et al. The impact of a telemedicine monitoring system on positive airway pressure adherence in patients with obstructive sleep apnea: a randomized controlled trial. Sleep. 2012;35(4):477-481.

55. Anttalainen U, Melkko S, Hakko S, Laitinen T, Saaresranta T. Telemonitoring of CPAP therapy may save nursing time. Sleep Breath. 2016;20(4):1209-1215.

56. Parikh R, Touvelle MN, Wang H, Zallek SN. Sleep telemedicine: patient satisfaction and treatment adherence. Telemed $J$ E Health. 2011;17(8):609-614.

57. Munafo D, Hevener W, Crocker M, Willes L, Sridasome S, Muhsin M. A telehealth program for CPAP adherence reduces labor and yields similar adherence and efficacy when compared to standard of care. Sleep Breath. 2016;20(2):777-785.

58. Hwang D, Chang J, Liang J, et al. Impact of interactive web-based education and automated feedback program on CPAP adherence for the treatment of obstructive sleep apnea. Am J Respir Crit Care Med. 2016;193:A4186.

59. Stepnowsky C, Edwards C, Zamora T, Barker R, Agha Z. Patient perspective on use of an interactive website for sleep apnea. Int J Telemed Appl. 2013;2013:239382.

60. Kuna ST, Shuttleworth D, Chi L, et al. Web-based access to positive airway pressure usage with or without an initial financial incentive improves treatment use in patients with obstructive sleep apnea. Sleep. 2015;38(8):1229-1236.

61. Cortez NG, Cohen IG, Kesselheim AS. FDA Regulation of mobile health technologies. $N$ Engl J Med. 2014;371(4):372-379.

62. Hardy W, Powers J, Jasko JG, Stitt C, Lotz G, Aloia MS. SleepMapper: a mobile application and website to engage sleep apnea patients in PAP therapy and improve adherence to treatment. 2014. Available from: http://cdn.sleepreviewmag.com/sleeprev/2014/06/SleepMapperAdherence-White-Paper.pdf. Accessed December 26, 2016.

63. Heatley EM, Harris M, Battersby M, McEvoy RD, Chai-Coetzer CL, Antic NA. Obstructive sleep apnoea in adults: a common chronic condition in need of a comprehensive chronic condition management approach. Sleep Med Rev. 2013;17(5):349-355.

64. Epstein LJ, Kristo D, Strollo PJ, et al. Clinical guideline for the evaluation, management and long-term care of obstructive sleep apnea in adults. J Clin Sleep Med. 2009;5(3):263-276.

65. Free C, Phillips G, Galli L, et al. The effectiveness of mobile-health technology-based health behaviour change or disease management interventions for health care consumers: a systematic review. PLoS Med. 2013;10(1):e1001362.

66. De la Torre-Diez I, Lopez-Coronado M, Vaca C, Aguado JS, de Castro C. Cost-utility and cost-effectiveness studies of telemedicine, electronic, and mobile health systems in the literature: a systematic review. Telemed $J$ E Health. 2015;21(2):81-85. 
67. Masa JF, Duran-Cantolla J, Capote F, et al. Effectiveness of home single-channel nasal pressure for sleep apnea diagnosis. Sleep. 2014;37(12):1953-1961.

68. Kim RD, Kapur VK, Redline-Bruch J, et al. An economic evaluation of home versus laboratory-based diagnosis of obstructive sleep apnea. Sleep. 2015;38(7):1027-1037.

69. Bruyneel M, Ninane V. Unattended home-based polysomnography for sleep disordered breathing: current concepts and perspectives. Sleep Med Rev. 2014;18(4):341-347.
70. Masa JF, Corral J, Pereira R, et al. Effectiveness of home respiratory polygraphy for the diagnosis of sleep apnoea and hypopnoea syndrome. Thorax. 2011;66(7):567-573.

71. Wilson SR, Cram P. Another sobering result for home telehealth - and where we might go next: comment on "A randomized controlled trial of telemonitoring in older adults with multiple health issues to prevent hospitalizations and emergency department visits". Arch Intern Med. 2012;172(10):779-780.

\section{Publish your work in this journal}

Smart Homecare Technology and TeleHealth is an international, peer-reviewed open access online journal publishing original research, reviews, editorials and commentaries on the application of technology to support people and patients at home and in assisted living centers to optimize healthcare and management resources. Specific topics in the journal include: Development and application of devices within the home and embedded in appliances; Healthcare provider communication and education tools; and drug ordering and adherence. The manuscript management system is completely online and includes a very quick and fair peer-review system, which is all easy to use. Visit http://www.dovepress.com/ testimonials.php to read real quotes from published authors.

Submit your manuscript here: https://www.dovepress.com/smart-homecare-technology-and-telehealth-journal 